\title{
Viabilidade dos espermatozoides criopreservados de touros, colhidos do epidídimo após 12 horas a $4^{\circ} \mathrm{C}$ Viability of cryopreserved bull spermatozoa collected
from the epididymis stored for 12 hours at $4^{\circ} \mathrm{C}$
}

\author{
Caroline Scott, ${ }^{* *}$ Tarcísio Torre Lourenço, ${ }^{* *}$ Diego Souza Moura, ${ }^{* *}$ Murillo Mansano Moscardini, ${ }^{* * *}$
} Cristiane dos Santos Honsho, ${ }^{* *}$ Fabiana Ferreira de Souza**

\begin{abstract}
Resumo
O objetivo deste estudo foi avaliar o efeito da refrigeração do epidídimo, sobre a viabilidade dos espermatozoides congelados. Foram colhidos dez pares de testículos/epidídimos de um abatedouro comercial. Um dos epidídimos foi refrigerado a $4^{\circ} \mathrm{C}$ durante 12 horas e o contralateral foi imediatamente processado. O epidídimo foi isolado, as células espermáticas extraídas e analisadas quanto à motilidade, vigor, concentração, morfologia e integridade da membrana. Após a análise, os espermatozoides foram congelados em diluente Botubov ${ }^{\circledR}$ (Botupharma Biotecnologia Animal, Botucatu, SP, Brasil) e descongelados para análise. O mesmo procedimento foi realizado com o testículo/epidídimo refrigerado. Os resultados evidenciaram maior viabilidade $(p \leq 0,05)$ das células pré-congelação para os parâmetros, número total de espermatozides (1,9 $\pm 1,2$ versus $0,9 \pm 0,9 \times 10^{9}$ espermatozoides), motilidade $(74,0 \pm 15,1$ versus $20,5 \pm 13,8 \%)$ e vigor $(3,7 \pm 0,5$ versus $1,7 \pm 0,8)$, e pós-congelação, motilidade ( $23,5 \pm 16,7$ versus $8,0 \pm 7,9 \%)$ e vigor $(2,0 \pm 0,8$ versus $0,8 \pm 0,8)$ quando os espermatozoides foram colhidos a partir de epidídimos processados imediatamente após o abate quando comparados aos mantidos 12 horas sob refrigeração, respectivamente. Conclui-se que 12 horas de refrigeração do epidídimo após o abate, prejudica a qualidade das células espermáticas, impossibilitando a congelação do sêmen.
\end{abstract}

Palavras-chave: bovino, cauda-epidídimo, célula-espermática, congelação.

\begin{abstract}
The purpose of this study was to evaluate effect of epididymis cooling on bovine frozen sperm viability. Ten pairs of testes/epididymes were collected of a commercial slaughterhouse; one epididymis from each pair was refrigerated at $4^{\circ} \mathrm{C}$ for 12 hours and the other immediately proceeded. Epididymis was isolated, sperm cells collected after epididymal slicing and then analyzed regarding to motility, vigor, total number of sperm, morphology and membrane integrity. Sperm cells were frozen in Botubov ${ }^{\circledR}$ extender (Botupharma Biotecnologia Animal, Botucatu, SP, Brazil) and thawed for semen analysis. The same procedure was performed with cooled testis/epididymis. Results demonstrated higher viability $(p \leq 0,05)$ of fresh cells to the total number of spermatozoa $(1,9 \pm 1,2$ versus $0,9 \pm 0,9 \times 10^{9}$ spermatozoa), sperm motility $(74,0 \pm 15,1$ versus $20,5 \pm 13,8 \%)$ and vigor $(3,7 \pm 0,5$ versus $1,7 \pm 0,8)$, and for pos-thawing motility $(23,5 \pm 16,7$ versus $8,0 \pm 7,9 \%)$ and vigor $(2,0 \pm 0,8$ versus $0,8 \pm 0,8)$ when spermatozoa were collected immediately post-slaughter than maintained cooling 12 hours, respectively. We conclude that 12 hours of epididymis cooling after slaughter decreases sperm cells quality.
\end{abstract}

Keywords: bovine, freezing, sperm-cell, tail-epididymis.

\section{Introdução}

Segundo o Censo Agropecuário do Instituto Brasileiro de Geografia e Estatística - IBGE (Brasil, 2012), o rebanho bovino brasileiro possui aproximadamente 211,3 milhões de cabeças. Em vista da posição do Brasil frente ao cenário mundial, o valor econômico e genético dos animais tem aumentado. A aplicação das técnicas de melhoramento genético animal associada às biotecnologias da reprodução é responsável por parte deste crescimento. Contudo, o material genético de touros de interesse zootécnico é perdido a todo o momento, por morte inesperada do animal. Uma forma de preservar o germoplasma destes animais é a colheita de espermatozoides do epidídimo (Martins et al., 2007). Este procedimento post mortem é considerado também uma importante ferramenta na utilização de espermatozoides de animais em risco de extinção (Lambrechts et al., 1999).

Os espermatozoides colhidos do epidídimo podem ser congelados (Peres et al., 2014), armazenados e utilizados para inseminação artificial (Martins et al., 2007), uma vez que Barker (1954) afirmou que a qualidade espermática e a congelabilidade das células espermáticas do epidídimo foi semelhante a do

${ }^{*}$ Recebido em 11 de junho de 2015 e aceito em 5 de outubro de 2015.

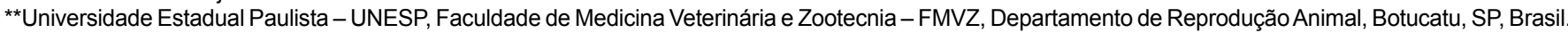

***Universidade de Franca - UNIFRAN, Medicina Veterinária, Hospital Veterinário, Franca, SP, Brasil.

Autor correspondente: Departamento de Reprodução Animal, FMVZ, UNESP, Distrito de Rubião Junior, s/nº, Botucatu, SP, Brasil, CEP 18.618-970. Fone:

+55 14 3880-2237, E-mail: fafesouza@fmvz.unesp.br. 
ejaculado em um estudo no qual foram inseminadas mais de 300 vacas e a taxa de prenhez foi em torno de $60 \%$. Adicionalmente, Stout (2012) encontrou maior motilidade espermática e menor taxa de reação do acrossomo após a descongelação de amostras oriundas do epidídimo, quando comparadas as do ejaculado.

Segundo Kanazawa et al. (2012) foi possível colher 2/3 da capacidade de armazenamento de células espermáticas contidas no epidídimo e há uma correlação entre a porcentagem de espermatozoides testiculares e a concentração de células colhidas do epidídimo. Barbosa et al. (2012) compararam a qualidade das células espermáticas do epidídimo, pré e póscongelação e verificaram motilidade em torno de $30 \%$ nas células descongeladas. Tal achado indica que estas amostras podem ser utilizadas na inseminação artificial, já que na maioria a qualidade obtida se iguala aos parâmetros obtidos em centrais de comercialização do sêmen (Crespilho et al., 2009).

Portanto, uma vez que é possível extrair as células espermáticas do epidídimo e criopreservá-las, mantendo a capacidade de fertilização, o objetivo deste estudo foi avaliar a viabilidade espermática comparando os resultados pré e pós-congelação das células colhidas imediatamente após o abate e 12 horas após a refrigeração do complexo testículo/epidídimo.

\section{Material e métodos}

\section{Delineamento experimental}

O estudo foi realizado de acordo com preceitos éticos recomendados pelo Colégio Brasileiro de Experimentação Animal (COBEA), após aprovação pelo Comitê de Ética no Uso de Animais (CEUA), sob protocolo $n^{\circ}$ 029/10.

Foram selecionados 10 pares de testículos/epidídimos de touros, colhidos em um abatedouro. Logo após o abate, os testículos/ epidídimos foram transportados em caixas térmicas a $4^{\circ} \mathrm{C}$ até $\mathrm{o}$ laboratório, em um prazo máximo de 30 minutos. As peças que apresentaram qualquer tipo de alteração (flacidez acentuada, secreção purulenta, assimetria acentuada entre os testículos) foram descartadas.

No laboratório, as peças foram separadas da bolsa testicular, lavadas com solução salina $0,9 \%$ e um dos testículo/epidídimo foi refrigerado em sacos plásticos, acomodados em caixas de isopor sem tampa a $4^{\circ} \mathrm{C}$, durante 12 horas.

A cauda do epidídimo do complexo testículo/epidídimo contralateral foi isolada e separada do tecido conectivo adjacente. Foram realizados vários cortes transversais e longitudinais sobre a cauda do epidídimo, com uma lâmina de bisturi para promover a extração das células espermáticas, segundo Castro et al. (2009). Esse procedimento foi realizado sobre uma placa de Petri, contendo $5,0 \mathrm{~mL}$ de solução salina $0,9 \%$ aquecida $\left(37^{\circ} \mathrm{C}\right)$. O conteúdo da placa de Petri foi vertido sobre um funil de plástico contendo um filtro de náilon (Semen Filter Colorado, Minitub do Brasil, Porto Alegre, RS, Brasil) acoplado a um tubo plástico graduado de $15 \mathrm{~mL}$. A placa de Petri foi lavada sobre o funil com $5,0 \mathrm{~mL}$ adicionais de solução salina $0,9 \%$, totalizando $10 \mathrm{~mL}$. O epidídimo refrigerado foi processado da mesma maneira, contudo, anterior à colheita as peças foram mantidas à temperatura ambiente entre 20 e 30 minutos.

A partir da concentração espermática da amostra colhida, a quantidade de diluente foi calculada em $\mathrm{mL}$. A amostra foi diluída em meio Botubov ${ }^{\circledR}$ (Botupharma Biotecnologia Animal,
Botucatu, SP, Brasil) e envasadas em palhetas francesas de 0,5 $\mathrm{mL}$, contendo $50 \times 10^{6}$ espermatozoides/palheta.

As palhetas foram acomodadas em uma grade de metal e refrigeradas a $4^{\circ} \mathrm{C}$, durante 4 horas. Após este período, a grade de metal, com as palhetas, foi transferida para uma caixa de poliestireno, contendo nitrogênio líquido acomodada $6 \mathrm{~cm}$ acima da superfície líquida, durante 20 minutos. Finalmente, as palhetas foram imersas no nitrogênio líquido e, posteriormente, armazenadas em botijão criogênico.

As palhetas foram descongeladas a $37^{\circ} \mathrm{C}$ em banho-maria, durante 30 segundos.

Após descongelamento das palhetas, análises laboratoriais foram realizadas para aferição da qualidade espermática.

\section{Análises laboratoriais}

Para avaliação da motilidade e vigor, uma alíquota de sêmen foi depositada sobre uma lâmina aquecida, recoberta por lamínula e observada em microscópio de contraste de fase, em aumento de 100X. A motilidade foi caracterizada pela presença de movimentos progressivos e classificada em escala percentual $(0$ a $100 \%$ ). O vigor foi caracterizado de acordo com a intensidade dos movimentos espermáticos e classificado de acordo com um escore de 0 a 5.

A concentração espermática foi avaliada após a diluição de 1:20 das amostras em formol-salina. As amostras diluídas foram depositadas na câmara de Neubauer e as células contadas em microscópio de contraste de fase, num aumento de 400X. O valor obtido foi expresso em bilhões $/ \mathrm{mL}$.

A morfologia espermática foi realizada utilizando-se o método Karras modificado (Papa et al., 1986). Uma alíquota da amostra foi depositada na extremidade de uma lâmina fosca e um esfregaço foi confeccionado. A lâmina foi fixada em metanol (1 passagem) e corada pelo método citado. Foram contadas 200 células, classificadas de acordo com os tipos de defeitos (maiores, menores ou normais) segundo Blom (1977), num aumento de 1.000X em microscópio de contraste de fase. Os valores foram classificados em escala porcentual.

A integridade da membrana espermática (coloração supravital) foi avaliada com $20 \mu \mathrm{L}$ de uma solução de eosina (eosina amarela $3 \%$ em solução salina 0.9\%) (Hafez, 1995) depositada em lâmina sobre $20 \mu \mathrm{L}$ da amostra. A amostra e a solução de eosina foram homogeneizadas e um esfregaço foi confeccionado. A leitura foi realizada em microscópio óptico, num aumento de 400X. As células coradas em vermelho foram consideradas com a membrana lesada (mortas) e as que não se coraram foram consideradas íntegras. O resultado foi expresso em escala porcentual.

\section{Análise estatística}

Todos os dados foram testados para normalidade pelo teste de Kolmogorov-Smirnov. As variáveis que não passaram no teste de normalidade (dados não paramétricos) foram avaliadas pelo teste de Mann-Whitney (Rank Sum Test) e pós-teste Student-Newman-Keuls. As variáveis que passaram no teste de normalidade (dados paramétricos) foram avaliadas pelo teste $\mathrm{t}$. $\mathrm{O}$ nível de significância considerado foi $p<0,05$. O software utilizado foi o Sigma Stat for Windows, versão 3.0.1 Systat Software inc, Richmond, CA, EUA. 


\section{Resultados e discussão}

A preservação do material genético é importante para manutenção das espécies, bem como no quesito econômico, uma vez que animais com alto valor genético podem ser perdidos a qualquer momento (Ehling et al., 2006). Neste sentido, a colheita de células oriundas do epidídimo pode ser uma fonte potencial de espermatozoides com o objetivo de preservar o material genético de um animal de alto valor. Apesar disso, quanto maior o tempo decorrido entre a morte do animal e a colheita das células, maior a degeneração tecidual, esgotamento e envelhecimento metabólico dos espermatozoides (Hishinuma et al., 2003; Muradás et al., 2006). A preservação do epidídimo sob refrigeração pode ser uma opção para preservar a integridade das células espermáticas. Contudo, neste estudo, os resultados indicaram que 12 horas de conservação do epidídimo a $4^{\circ} \mathrm{C}$ reduziram a motilidade espermática $(p<0,001)$, na maioria das amostras. A queda na motilidade após a refrigeração do epidídimo a $18-20^{\circ} \mathrm{C}$ também foi descrita por Bertol, et al. (2013). Silva et al. (2012) afirmaram que a motilidade espermática diminui de $60 \%$ para $18,8 \%$, as 12 e 36 horas após a refrigeração do epidídimo de touros, respectivamente, embora os autores não tenham avaliado a motilidade inicial. Já Nichi et al. (2008) encontraram marcado efeito negativo, especialmente no potencial mitocondrial, quando o epidídimo foi mantido por 2 a 3 horas a $34^{\circ} \mathrm{C}$, comparado a refrigeração a $4^{\circ} \mathrm{C}$. Tais resultados comprovam que a melhor maneira de preservar as células é pelo frio, independentemente da sua condição, contidas ou não no epidídimo.

A motilidade é o parâmetro mais suscetível a condições deletérias do que qualquer outra característica associada à viabilidade espermática (Soler et al., 2003; Monteiro et al., 2013), o que pôde ser observado no epidídimo que foi refrigerado. Parece, porém, existir diferença entre as espécies, já que em carneiros Muradás et al. (2006) relataram viabilidade espermática com 48 horas de refrigeração dos epidídimos, em cães os relatos variam de 5 horas (Yu e Leibo, 2002) a 4 dias (Ponglowhapan et al., 2006) e em cavalos não há diferenças consideráveis entre 24 e 48 horas (Monteiro et al., 2013).

Contradizendo os relatos de Bissett e Bernard (2004), que afirmaram que a manutenção constante da temperatura de refrigeração diminui a degradação tecidual levando a uma maior porcentagem de espermatozoides viáveis, o presente estudo manteve as peças sob constante temperatura, o que não contribuiu para manter a motilidade dos espermatozoides oriundos das peças refrigeradas em comparação as peças processadas a fresco, na avaliação das amostras após a descongelação. Apesar disto, a morfologia celular $(p=0,111)$ e a integridade da membrana espermática $(p=0,796)$ não se alteraram durante a refrigeração. Segundo Soler et al. (2003) a porcentagem de espermatozoides morfologicamente normais não se altera quando o epidídimo é refrigerado por até três dias, incluindo a porcentagem de gotas citoplasmáticas que não sofre alteração durante o armazenamento (Filliers et al., 2008). Tal fato se assemelha ao presente estudo que não encontrou diferenças significativas entre a morfologia espermática das amostras colhidas dos epidídimos fresco e após 12 horas de conservação.

Os parâmetros concentração total, número de células normais e com defeitos e integridade de membrana não foram avaliados após a descongelação.

$\mathrm{Na}$ Tabela 1 encontram-se demonstrados os parâmetros espermáticos avaliados após descongelação de espermatozoides oriundos de epidídimos frescos e refrigerados. to coldes coldos do epídimo de 10 touros post mortem, antes e após a refrigeração do órgão

\begin{tabular}{llllc}
\hline & A & A1 & B & B1 \\
\hline Motilidade (\%) & $74,0 \pm 15,1^{\mathrm{a}}$ & $23,5 \pm 16,7^{\mathrm{b}}$ & $20,5 \pm 13,8^{\mathrm{b}}$ & $8,0 \pm 7,9^{\mathrm{c}}$ \\
Vigor (0-5) & $3,7 \pm 0,5^{\mathrm{a}}$ & $2,0 \pm 0,8^{\mathrm{b}}$ & $1,7 \pm 0,8^{\mathrm{b}}$ & $0,8 \pm 0,8^{\mathrm{c}}$ \\
Concentração total $\left(\times 10^{9}\right)$ & $1,9 \pm 1,2^{\mathrm{a}}$ & -- & $0,9 \pm 0,9^{\mathrm{b}}$ & -- \\
Normal (\%) & $84,7 \pm 7,3^{\mathrm{a}}$ & -- & $72,9 \pm 21^{\mathrm{a}}$ & -- \\
Defeitos maiores (\%) & $8,1 \pm 7,3^{\mathrm{a}}$ & -- & $10,8 \pm 12,9^{\mathrm{a}}$ & -- \\
Defeitos menores (\%) & $7,5 \pm 5,2^{\mathrm{a}}$ & -- & $11,3 \pm 9,5^{\mathrm{a}}$ & -- \\
Integridade de membrana (\%) & $76,7 \pm 16,6^{\mathrm{a}}$ & -- & $78,3 \pm 9,8^{\mathrm{a}}$ & -- \\
\hline A:Espermatozoin
\end{tabular}

A: Espermatozoides colhidos do epidídimo imediatamente após o abate; $A 1$ : Espermatozoides $A$ pós-descongelação; B: Espermatozoides colhidos do epidídimo mantido a $4^{\circ} \mathrm{C}$ durante 12 horas após o abate; B1: Espermatozoides B pós-descongelação.

Como já referido por outros autores (Martins et al., 2007; Bartels et al., 2000), o principal defeito espermático encontrado foi a gota citoplasmática distal, o que já era esperado devido ao processo de maturação final dos espermatozoides no epidídimo (Bartels et al., 2000; Tajik et al., 2007). Entretanto, especula-se que manipulação das amostras (Jones, 1986; Cooper, 2011), durante a passagem pelo filtro de náilon, antes da avaliação pode ter contribuído para menor porcentagem de gotas citoplasmáticas distais (GCD) no presente estudo (6\%) quando comparada aos estudos de Tajik et al. (2007) que encontraram apenas 9,9\% de células oriundas da cauda do epidídimo sem GCD.

Em 2005, Soler et al. descreveram lesões na membrana plasmática de espermatozoides de veados oriundos do epidídimo refrigerado a $5^{\circ} \mathrm{C}$, contrariando os achados descritos pelo mesmo grupo (Soler et al., 2003) que afirmaram que a integridade de membrana não foi afetada pela refrigeração dos epidídimos na mesma temperatura.

Segundo os relatos de Moraes et al. (1998), os parâmetros espermáticos encontrados, das células colhidas imediatamente após o abate, classificariam os touros como aptos para reprodução, considerando a motilidade superior a $50 \%$, vigor espermático superior a dois e número de espermatozoides, morfologicamente normais superior a $60 \%$.

Em touros, os relatos mais recentes a respeito da fertilidade dos espermatozoides oriundos do epidídimo de bovinos os quais utilizaram a FIV (fertilização in vitro; Martins et al., 2007; 2009) e encontraram taxa de formação de blastocistos similares entre as células provenientes do ejaculado e epidídimo (Stout, 
2012). Contudo, este não foi o primeiro sucesso da aplicação das células espermáticas proveniente do epidídimo, já que Barker, em 1954, descreveu a inseminação artificial de mais de 300 vacas. Além disso, Aman e Griel (1974) também realizaram a inseminação artificial dos espermatozoides oriundos da cauda do epidídimo obtendo uma taxa de gestação de $84 \%$, contra os $94 \%$ quando as vacas foram inseminadas com espermatozoides ejaculados. Desta forma, é possível afirmar que os espermatozoides recuperados do epidídimo podem ser utilizados para FIV e inseminação artificial, especialmente, quando colhidos logo após a morte do animal.

\section{Conclusão}

Com base nos achados foi possível concluir que os espermatozoides do epidídimo podem ser congelados, com viabilidade pós-descongelação, desde que sejam colhidos até 30 minutos após a morte do animal.

\section{Agradecimentos}

A FAPESP processo $n^{\circ}$ 2008/11685-6 e ao frigorífico Franca Boi, Franca, SP.

\section{Referências}

AMANN, R.P.; GRIEL, L.C JR. Fertility of bovine spermatozoa from rete testis, cauda epididymis, and ejaculated sperm. Journal of Dairy Science. v. 57, p. 212-219, 1974.

BARBOSA, L.M.; KANAZAWA, M.Y.; PERES, A.R.; SOUZA, F.F. Viabilidade do sêmen congelado obtido do epidídimo de touros post-mortem. Revista Brasileira de Ciência Veterinária. v. 19, n. 3, p. 1-5, 2012.

BARKER, C.A.V. Low temperature preservation of bovine epididymal spermatozoa. Canadian Journal of Comparative Medicine and Veterinary Science., v. 18, p. 390-393, 1954.

BARTELS, P.; LUBBE, K.; KILIAN, I.; FRIEDMANN, Y.; VAN DYK, G.; MORTIMER, D. In vitro maturation and fertilization of lion (Panthera leo) oocytes using frozen-thawed epididymal spermatozoa recovered by cauda epididymectomy of an immobilized lion. Theriogenology, v. 53, p. 325, 2000.

BERTOL, M.A.F.; WEISS, R.R.; THOMAZ-SOCCOL, V.; KOZICKI, L.E.; FUJITA, A.S.; ABREU, R.A.; GREEN, K.T. Viability of Bull Spermatozoa Collected from the Epididymis Stored at $18-20^{\circ} \mathrm{C}$. Brazilian Archives of Biology and Technology, v.56, n.5 p. 777783, 2013.

BISSET, C.; BERNARD, R.T.F. The effect of prolonged cold storage of eland (Taurotragus oryx) cauda epididymides on the spermatozoa: possible implications for the conservation of biodiversity. Theriogenology, v. 63, p. 1592-1604, 2004.

BLOM, E. Sperm morphology with reference to bull infertility. In: FIRST ALL-INDIA SYMPOSIUM ON ANIMAL REPRODUCTION. 61-81. 1977. Anais...Ludhiana.

BRASIL. Ministério do Planejamento, Orçamento e Gestão. Instituto Brasileiro de Geografia e Estatística. Produção da Pecuária Municipal, Efetivo dos rebanhos em 31.12 e variação anual, segundo as categorias - Brasil - 2011-2012. Disponivel em: <http://www.ibge.gov.br/home/estatistica/economia/ppm/2012/ default_pdf.shtm>. Acesso em: jan. 2014.

CASTRO, J.B.; CASAS, V.F.; SOUZA, F.F. Viabilidade dos espermatozóides colhidos do epidídimo de touros 24 horas postmortem. In: CONGRESSO BRASILEIRO DE REPRODUÇÃO ANIMAL. 64. 2009. Anais...Belo Horizonte: Colégio Brasileiro de Reprodução Animal.

COOPER, T.G. The epididymis, cytoplasmic droplets and male fertility. Asian Journal of Andrology, v. 13, p. 130-138, 2011.
CRESPILHO, A.M.; PAPA, F.O.; MARTINS JUNIOR, A.; DELLAQUA JUNIOR, J.A. Evaluation of frozen bovine semen: how do semen collection and processing centers evaluate the quality of commercialized samples? Veterinária e Zootecnia, v. 16, p. 335-342, 2009.

EHLING, C.; RATH, D.; STRUCKMANN, C.; FRENZEL, A.; SCHINDLER, L.; NIEMANN, H. Utilization of frozen-thawed epididymal ram semen to preserve genetic diversity in Scrapie susceptible sheep breeds. Theriogenology, v. 66, p. 2160-2164, 2006.

FILIERS, M; RIJSSELAERE, T.; BOSSAERT, P.; DE CAUSMAECKER, V.; DEWULF, J.; POPE, C. E.; VAN SOOM, A. Computer-assisted sperm analysis of fresh epididymal cat spermatozoa and the impact of cool storage (4 8C) on sperm quality. Theriogenology, v. 70, p. 1550-1559, 2008.

HAFEZ, E. S. E. Reprodução animal. 6.ed. São Paulo: Manole, 1995, $582 \mathrm{p}$.

HISHINUMA, M.; SUZUKI, K.; SEKINE, J. Recovery and criopreservation of sika deer (Cervus nippon) spermatozoa from epididymes stored at $4^{\circ} \mathrm{C}$. Theriogenology, v. 59, n. 3-4, p. 813820, 2003.

JONES, R. Preparation of a plasma membrane-rich fraction from rat spermatozoa. Journal of Reproduction and Fertility, v. 77, p. 435-449, 1986.

KANAZAWA, M. Y.; SCOTT, C.; WILGES, C.H.M.; DIAS, L. G. G. G.; SOUZA, F. F. Correlação da circunferência escrotal, citologia testicular e parâmetros do sêmen do epidídimo de touros. Enciclopédia Biosfera, v. 8, n. 15, p. 517-527, 2012.

LAMBRECHTS, H.; van NIEKERK, F.E.; COETZER, W.A.; CLOETE, S.W.; van der HORST, G. The effect of cryopreservation on the survivability, viability and motility of epididymal African buffalo (Syncerus caffer) spermatozoa. Theriogenology, v. 52, p. 1241-1249, 1999.

MARTINS, C.F.; DRIESSEN K.; COSTA P.M.; CARVALHO-NETO, J.O., DE SOUSA, R.,V.; RUMPF, R.; DODE, M. N. Recovery, cryopreservation and fertilization potential of bovine spermatozoa obtained from epididymides stored at $5^{\circ} \mathrm{C}$ by different periods of time. Animal Reproduction Science., v. 116, p. 50-57, 2009.

MARTINS, C.F.; RUMPF, R.; PEREIRA, D.C.; DODE, M.N. Cryopreservation of epididymal bovine spermatozoa from dead animals and its uses in vitro embryo production. Animal Reproduction Science, v. 101, p. 326-331, 2007. 
MONTEIRO, G.A.; GUASTI, P.N.; HARTWIG, F.P.; DELLAQUA JR., J.A.; ALVARENGA, M.A.; PAPA, F.O. Cooling of ejaculated and epididymal stallion sperm. Arquivo Brasileiro de Medicina Veterinária e Zootecnia, v. 65, n. 3, p. 681-686, 2013.

MORAES, J.C.F.; HORN, M.M.; ROSADO JR, A.G. Exame andrológico em touros: qualidade dos indicadores da aptidão reprodutiva em distintos grupos raciais. Ciência Rural., v. 28, p. 647-652, 1998.

MURADÁS, P.R; WEISS, R.R.; KOZICKI, L.E.; GRANEMANN, L.C.; SANTOS, I.W.; PIMPÃO, C.T. Alguns parâmetros de viabilidade de espermatozoides equínos colhidos por vagina artificial e por lavagem da cauda do epidídimo. Archives of Veterinary Science, v. 11, p. 69-74, 2006.

NICHI, M.; RIJSSELAERE, T.; GOOVAERTS, I. G. F.; VAN SOOM, A.; BARNABE, V. H.; DE CLERCQ, J. P. B.; BOLS, P. E. J. Effect of epididymis storage temperature and cryopreservation on mitochondrial potential, membrane integrity and motility of bovine epididymal sperm. Reproduction of Domestic Animals, v. 43, p. 167, 2008.

PAPA, F.O.; ALVARENGA, M.A.; BICUDO, S.D.; LOPES, M.D.; RAMIRES, P.R.N. Coloração espermática segundo Karras modificado pelo emprego do Barbatimão (Sthyphnodendrum barbatiman). In: CONGRESSO DE BIOLOGIA CELULAR, 86. 1986. Anais...Rio de Janeiro

PERES, A.R.; BARBOSA, L.M.; KANAZAWA, M.Y.; MARTINS, M.I.M.; SOUZA, F.F. Criopreservación de espermatozoides bovino extraídos de la cola del epidídimo utilizando métodos convencional y automatizado. Archives of Medicine Veterinary Science, v. 46, 2014 (in press).
PONGLOWHAPAN, S.; CHATDARONG, K.; SIRIVAIDYAPONG, S.; LOHACHIT, C. Freezing of epididymal spermatozoa from dogs after cool storage for 2 or 4 days. Theriogenology, v. 66, p. 16331636, 2006.

SILVA, V.; LEAL, J.; CARDOSO, R. Evaluation of epididymal bovine sperm after postmortem short-term storage at 5 degrees C. Reproduction of Domestic Animals, v. 47, p. 440, 2012.

SOLER, A.J.; ESTESO, M.C.; FERNANDÉZ-SANTOS, M.R.; GARDE, J.J. Characteristics of Iberian red deer (Cervus elaphus hispanicus) spermatozoa cryopreserved after storage at $5^{\circ} \mathrm{C}$ in the epididymis for several days. Theriogenology, v. 64, p. 15031517, 2005.

SOLER, A.J.; PEREZ-GUZMSOLER, A.J.; PEREZ-GUZMAN, M.D.; GARDE, J.J. Storage of red deer epididymis for four days at $5^{\circ} \mathrm{C}$ : effects on sperm motility, viability, and morphological integrity. Journal of Experimental Zoology, v. 295, p. 188-199, 2003.

STOUT, M.A. Comparison of epididymal and ejaculated sperm collected from the same Holstein bulls. 2012. $203 \mathrm{f}$. Dissertation (Doctor of Philosophy) - Faculty of the Louisiana State University and Agricultural and Mechanical Collage - The School of Animal Sciences - Louisiana State University, Louisiana, 2012.

TAJIK, P.; ARMAN, A.; TAKTAZ, T. Bovine epididymal sperm morphology obtained from caput, corpus and cauda epididymides. Pakistan Journal of Biological Science, v. 10, n. 21, p. 3936-3939, 2007.

YU, I.; LEIBO, S.P. Recovery of motile, membrane-intact spermatozoa from canine epididymides stored for 8 days at $4^{\circ} \mathrm{C}$. Theriogenology, v. 57, p. 1179-1190, 2002. 